\title{
VIOLÊNCIA ESCOLAR: UMA REFLEXÃO SOBRE A VIOLÊNCIA DA ESCOLA CONTRA A CRIANÇA
}

\author{
SCHOOL VIOLENCE: A REFLECTION ON SCHOOL VIOLENCE AGAINST \\ CHILDREN
}

\author{
Julia Bastos Lopes ${ }^{1}$ \\ Denise Paiva d’Ávila Melo²
}

\begin{abstract}
RESUMO: O presente artigo tem como objetivo refletir e expor a relação entre os conceitos de violência e autoridade no contexto escolar e, especialmente na relação professor-aluno. Assim construindo conhecimentos sobre formas de enfrentar esses tipos de violações dos direitos das crianças praticadas no ambiente escolar. A preocupação e interesse em estudar esse acontecimento ocorre pela alta quantidade de crianças que chegam no ensino médio e na fase adulta e possuem problemas/traumas/dificuldades nessas fases devido a esses acontecimentos abordados no artigo. Logo, com a ajuda das práticas participativas, pode-se reparar o valor da ação colaborativa na escola, elaborando ações que visam o diálogo e a aproximação de toda a comunidade escolar, buscando uma escola acolhedora.
\end{abstract}

Palavras-chave: Escola. Violência escolar. Educação Infantil. Pedagogia. Professor-aluno.

ABSTRACT: This article aims to reflect and expose the relation between the concepts of violence and authority in the school context and, especially in teacher-student relationship. And thus developing knowledge about ways to face these types of violations of children's rights practiced in the school environment. The concern and interest in studying this event occurs due to the high number of children who arrive in high school and adulthood and have problems/traumas/difficulties in these phases due to these situations addressed in the article. Therefore, with the help of participatory practices, one can repair the value of collaborative action in the school, elaborating actions aimed at dialogue and bringing the whole school community closer, pursuing a welcoming school.

\footnotetext{
I Graduanda em Pedagogia pela Universidade Veiga de Almeida localizada no Estado do Rio de Janeiro. Autora de jogo de tabuleiro chamado "Juntos nessa História" onde foi elaborado na disciplina Laboratório de Análise e Produção Didática do curso de Pedagogia, o jogo apresenta uma proposta de contextualização no ensino da história africana, utilizando como recurso didático um jogo de tabuleiro que aborda assuntos históricos e atuais da cultura afro, com o objetivo de facilitar o processo de aprendizagem dos alunos. Conclusão do curso de Maquiagem Cinematográfica ministrado pela Academia Internacional de Cinema em 2017.

${ }^{2}$ Mestre em Educação, Professora do Curso de Pedagogia da Universidade Veiga de Almeida
} 
Keys-words: School. School Violence. Childhood Education. Pedagogy. Teacher-student relationship

\section{INTRODUÇÃO}

A Educação Infantil, como etapa inicial da educação básica, é de extrema importância para o desenvolvimento das habilidades que possibilitarão a compreensão e interiorização do mundo humano pela criança. Esta fase tem como finalidade o desenvolvimento das crianças até cinco anos de idade e é nessa etapa que elas descobrem novos valores, sentimentos, costumes, ocorrendo também o desenvolvimento da autonomia, da identidade e da interação com outras pessoas.

O objetivo deste trabalho é desenvolver uma reflexão sobre a formação de professores ao tratar de crianças da educação infantil e destacar o uso da violência no contexto escolar. A principal proposta deste trabalho é buscar responder à questão norteadora: por que crianças da educação infantil sofrem maus tratos dentro escola? E assim, desenvolver uma atenção sobre a formação docente ao encarar a violência infantil.

A principal hipótese é que muitos desses profissionais não possuem a formação em pedagogia exigida pela lei e que existe a relação de autoritarismo pedagógico do educador em sala de aula. Com isso, este trabalho também consiste em identificar os principais tipos de violência que são praticadas por eles.

Para a maior parte da população, maus tratos significa abuso físico ou sexual, entretanto esses dois são só um dos exemplos. Esses maus tratos se agrupam entre negligência, abuso emocional, psicológico e entre outros assim possuindo sofrimentos psíquicos e afetivos que deixam profundos traumas para toda a existência. Assim, neste artigo, nosso objetivo será analisar o papel do educador a respeito do seu papel diante da violência na escola e principalmente dentro da sala de aula. Tal esforço se justifica pela importância do tema, visto que tais atitudes comprometem a vida dessas crianças resultando a graves danos e a traumas profundos nas vítimas. 
Por fim, cabe enfatizar que tal temática é muito abordada pelo sociólogo francês Pierre Bourdieu que elaborou o conceito violência simbólica, o qual aborda uma forma de violência exercida pelo corpo. Ocorrendo no meio educacional onde exclui o aluno que não se enquadra nos padrões impostos pela instituição, o levando-o ao desestímulo e à exclusão.

$\mathrm{O}$ interesse com este objeto de estudo foi percebido entre conversas de amigos e conhecidos, e principalmente pelas minhas próprias experiencias na educação infantil, que testemunharam ou foram vítimas de abuso psicológico ou abuso verbal, como: humilhar a pessoa na sala de aula, criticá-la por não seguir a ideia do aluno perfeito, insultá-la etc.

\section{VIOLÊNCIA ESCOLAR}

Qualquer reflexão sobre a violência escolar e suas consequências necessita, inicialmente, que se deixe claro o que se pretende dizer quando se fala de violência. Porém, vale ressaltar que pode ser bastante arriscado querer definir um tema tão debatido no meio intelectual, entre juristas e nos mais variados círculos de conversas do dia a dia de qualquer pessoa (PEREIRA, 2016).

Etimologicamente, a palavra violência

vem do latim violentia, que significa violência, caráter violento ou bravio, força. O verbo violare significa tratar com violência, profanar, transgredir. Tais termos devem ser referidos a vis, que quer dizer força, vigor, potência, violência, emprego da força física, mas também quantidade, abundância, essência ou caráter essencial de uma coisa. Mais profundamente, a palavra vis significa a força em ação, o recurso de um corpo para exercer sua força e, portanto, a potência, o valor, a força vital. (MICHAUD, 200I, p. 8 apud PEREIRA, 2016).

Michaud (1989) considera que há violência quando, numa situação de interação, um ou mais atores agem de maneira direta ou indireta, maciça ou esparsa, causando danos a uma ou várias pessoas em graus variáveis, seja em sua integridade física, moral, em suas posses ou em participações simbólicas e culturais (MICHAUD, 1989, p. io e II apud PEREIRA, 2016).

Já Assis e Marriel (2010) comentam que violência não é fácil de se conceituar, pois é um fenômeno complexo e multicausal, ela atinge todas as pessoas, grupos, instituições e 
povos, e por todos é produzida. As diferentes formas de violência são também classificadas pela Organização Mundial da Saúde - OMS, segundo a natureza dos atos cometidos. Destacamos (BRASIL, 200I; KRUG et al., 2002 apud ASSIS e MARRIEL, 2010): violência física, violência psicológica, violência sexual e negligência ou abandono.

Sendo categorizados dessa forma para melhor compreensão sobre o assunto, vale ressaltar que as percepções de violência irão variar de pessoa para pessoa, de grupo para grupo, pois cada indivíduo tem sua forma de perceber violência, gerando assim situações diversas quando estão vivenciando a situação (SOUZA, 2017).

A OMS definiu violência como sendo

[...] o uso intencional de força ou poder físico, ameaçado ou real, contra si mesmo, outra pessoa, ou contra um grupo ou comunidade, que resulta em ou tem uma alta probabilidade de resultar em prejuízo, morte, dano psicológico, mau desenvolvimento ou privação (UNESCO, I98I apud CANDIDO, 2019).

Nas palavras de Debarbieux (2003, apud CANDIDO, 2019) podemos referenciar e conceituar a violência como sendo uma maneira de usar a agressividade de forma intencional e excessiva para ameaçar, amedrontar ou cometer algum ato que cause dor e resulte em algum tipo de trauma, seja ele físico ou psicológico.

No que se refere à violência que é praticada no espaço escolar, existem vários pesquisadores que estudam esse tema tão relevante, dando assim sustentação teórica necessária para o desenvolvimento deste artigo, dentre eles, destacamos Michaud (1989), Debarbieux (2003), Charlot (2002), Sposito (2001) e Bourdieu (2001).

A violência escolar pode aparecer muitas das vezes de forma disfarçada, natural e silenciosa considerada como violência simbólica, colocando em evidência as questões de classe social. Segundo o sociólogo francês Pierre Bourdieu (200I, apud PEREIRA, 2016), nas obras em que trata do tema sobre violência, traz a ideia de constituição de um novo sentido para este tipo de violência, o que nas suas palavras conceituou como violência simbólica.

Segundo Jubé et al (202I) violência simbólica é um conceito elaborado pelo sociólogo francês Pierre Bourdieu (1990), no qual aborda uma forma de violência exercida 
pelo corpo sem coação física, em que causa danos morais e psicológicos, e até mesmo processo de aculturação, ou seja, imposição de uma cultura dominante. Sendo um grande problema na educação, pois ainda que não se apresente nitidamente, está inserida no processo educacional por meio de atitudes consideradas banais, mas que reverberam na subjetividade e na percepção da relação do sujeito e da sociedade (JUBÉ et al, 202I).

Este tipo de violência é a mais difícil de ser percebida na sociedade, por se expressar na imposição legitima e dissimulada por meio da interiorização dos valores da classe dominante, onde a submissão do dominado pode ser evidenciada pela aceitação de regras e valores, pois ele não entende que está sendo submisso ou dominado (PEREIRA, 2016). De acordo com Souza (2017), tomando como base a autora Maria Vasconcelos para tal abordagem:

\begin{abstract}
Através do uso da noção de violência simbólica ele tenta desvendar o mecanismo que faz com que os indivíduos vejam como "natural" as representações ou as ideais sociais dominantes. A violência simbólica é desenvolvida pelas instituições e pelos agentes que as animam e sobre a qual se apoia o exercício da autoridade. Bourdieu considera que a transmissão pela escola da cultura escolar (conteúdos, programas, métodos de trabalho e de avaliação, relações pedagógicas, práticas linguísticas), própria à classe dominante, revela uma violência simbólica exercida sobre os alunos de classes populares. (VASCONCELOS, 2002, p. 8o-8r apud SOUZA, 2017, p.18)
\end{abstract}

A violência simbólica ocorre no meio educacional na medida em que exclui o aluno que não se enquadra nos padrões desejáveis de desempenho e comportamento pelo sistema educacional, logo deixando-o às margens do processo, o que, posteriormente, o leva ao desestímulo e finalmente à exclusão (JUBÉ et al., 202I).

Para Souza (2017), os professores nos dias de hoje têm sido cada vez mais desvalorizados em sua profissão e através dos estudos sociológicos pôde compreender o crescimento da violência e suas transformações das relações entre aluno e professor ao longo do tempo. Não é de hoje que ouvimos falar de violência escolar dentro da prática docente, porém o professor impunha sua autoridade sob formas de punição física, como por exemplo, usava a palmatória, colocava o aluno ajoelhado no milho ou em pé virado para parede, colocava no aluno alegorias como orelhas de burro. 
O uso da palmatória foi muito utilizado e antigamente os alunos até presenteavam seus professores com a palmatória, para demonstrar que eram submissos à sua autoridade. Por sua vez, nos dias atuais o uso desses recursos não é mais permitido e a relação social entre o aluno e professor se transformou muito, colocando em análise como será transmitido pelo professor o seu papel de dominante sobre o aluno (SOUZA, 2017).

Pode-se afirmar que mesmo quando não exercida com autoritarismo, a prática de autoridade do professor configura uma violência simbólica, pois os moldes da instituição escolar com suas normas e regras que são impostas colaboram para que ocorram situações bem conflituosas sendo categorizada como violência institucional (SOUZA, 2017).

A violência simbólica é utilizada como forma de dominação, inclusive pelos professores, posto que os símbolos são instrumentos estruturados e estruturantes de conhecimento. Mas também os professores estão sujeitos a essa violência, ao ter que cumprir prazos, programas, preencher formulários, cadernetas, seguir apostilas etc., ou seja, atender às determinações vindas de cima, sem que o professor tenha participação na sua elaboração (ASSIS, 20ıo).

Ainda nas palavras de Assis (2010), nas instituições escolares, percebe-se o professor com um duplo papel: de um lado como representante do poder, exerce o papel de dominador; de outro, o papel de dominado, submetendo-se a regulamentos e exigências burocraticamente estabelecidas, em que os aspectos organizacionais administrativos se sobrepõem à pedagogia.

\subsection{Outros tipos de violência}

Um dos principais tipo de violência vistos na escola é o preconceito racial, muitas vezes refletido na escola entre os alunos, é fruto da falta de conhecimento, sendo assim, é fundamental que o professor trabalhe em sala de aula a consciência moral, ética e cultural, possibilitando ao aluno o desenvolvimento da capacidade de estabelecer valores e saberes e agir de forma coerente a eles (TUONO e VAZ, 2017). A noção de raça em nossa sociedade é ainda um parâmetro de classificação das pessoas. E a ideia de superioridade entre elas é 
capaz de desencadear comportamentos discriminatórios inclusive entre as crianças (ASSIS, 2010).

Para Boni (2008 apud Tuono e Vaz, 2017), a temática sobre racismo gera muitas polêmicas, fato este que dificulta o trabalho do professor, pois alguns têm dificuldades em trabalhar com os conflitos que as questões raciais geram, outros, não possuem conhecimento necessário para atuar com o tema. Outro fator que dificulta a abordagem acerca da cultura africana é o preconceito entre os próprios professores, segundo Boni (2008) a escola está repleta de práticas racistas, discriminatórias e preconceituosas.

\footnotetext{
Percebe-se que no ambiente escolar as situações de conflito que poderiam promover a interação, o conhecimento e o respeito às diferenças e às peculiaridades das diversas culturas ali presentes, não são bem aproveitadas pelo professor, que muitas vezes, veem na situação que se apresenta, algo constrangedor, gerador de tensão e não sabem como trabalhar adequadamente com a questão se omitindo ou tratando isoladamente o fato. (BONI, 2008, p.2 apud TUONO e VAZ, 2017, p.207).
}

A análise realizada no livro O Drama Racial das Crianças Brasileiras: socialização entre pares e preconceito, da professora de sociologia da Universidade de Minas Gerais (UFMG) Rita Fazzi (apud Assis, 2017), mostra como se estabelecem as relações das crianças entre sete e nove anos, no cotidiano escolar, e de como o preconceito racial ali se apresenta. A autora adentra no universo lúdico das crianças, utiliza jogos, bonecos e fotografias de pessoas de cores diferentes e sugere que elas construam histórias sobre os personagens, inclusive sobre suas possíveis profissões.

Por intermédio da observação participante, a professora captou a reprodução de situações de preconceito e discriminação no espaço escolar, especialmente no horário do recreio e em atividades extraclasse. Entre as conclusões, uma se refere à constatação de que desde a tenra idade os estudantes apresentam a noção de raça como um parâmetro de classificação das pessoas.

Outra do tipo de violência que mais chama a atenção nas escolas é a homofobia, ou o tratamento discriminatório sofrido por jovens de ambos os sexos tidos como homossexuais, legitimada por moralismos em nome da masculinidade (ABRAMOVAY, 2015). A diferença entre os sexos existe em todos os tipos de sociedades, sendo mais antiga 
do que elas próprias. As diferenças de gênero emergem das relações humanas, mediadas pela cultura, em que encontramos aprendizados diferentes para homens e mulheres (ASSIS, 2017). O conceito de gênero diz respeito ao conjunto das representações e práticas culturais e sociais constituídas a partir das diferenças biológicas entre os sexos.

É comum confundir os conceitos de sexo e gênero. Enquanto sexo diz respeito, basicamente, ao aspecto anatômico dos corpos, o conceito de gênero toma por base noções como masculino e feminino em relação, como atributos socialmente construídos. Ou seja, sexo, está ligado às características biológicas entre macho e fêmea de determinada espécie; e gênero diz respeito à construção cultural e histórica, ou seja, emerge das relações sociais e dependem das interpretações culturais (HEILBORN,1994; OAKLEY, 1972; LANE, 1995; SCOTT 1995 APUD ASSIS, 2017).

Discutir gênero e sexualidade é essencial em nossa sociedade e principalmente na escola, que se torna locus privilegiado para a reprodução de papéis de gênero e modelos de sexualidade que continuam oprimindo os educandos (MONTEIRO e RIBEIRO, 2020). Foucault (1988, p. Ioo APUD MONTEIRO E RIBEIRO, 2020) escreve que "a Sexualidade é o nome que se pode dar a um dispositivo histórico”. Não se pode limitá-la à biologia que a naturaliza em vê-la a partir de uma aura proibitiva cercada de tabus, obscurantismo e sentido de pecado que comumente as igrejas lhe atribuem.

Uma questão importante é a discriminação religiosa. A escola é o espaço onde se encontram crianças, adolescentes e jovens de diferentes níveis e grupos sociais. Assim, indivíduos com diferentes crenças e identidades, inclusive religiosas, convivem e se relacionam cotidianamente. A discriminação contra adeptos de religiões protestantes, pentecostais e neopentecostais é bastante recorrente, assim como discriminação contra religiões afro-brasileiras (ABRAMOVAY, 2015). A categoria macumbeira é o xingamento ao qual correspondem seguidores das religiões afro-brasileiras, e está sempre relacionada ao mal e ao errado.

A discriminação relacionada às pessoas com deficiência física mostra como as políticas de inclusão social de pessoas com deficiência física ou intelectual trouxeram para a escola aqueles antes excluídos de sua sociabilidade e construção de conhecimento 
(ABRAMOVAY, 2015). Porém, isso não quer dizer que as escolas, na prática, estejam preparadas para receber pessoas com deficiência e criar condições propícias para a convivência delas no ambiente escolar.

\section{A AUTORIDADE DO PROFESSOR E SEU PAPEL}

A expressão autoridade docente carrega em sua formulação um conjunto consideravelmente amplo de elementos e significados. De forma explícita, traz logo de cara o complexo conceito de autoridade, cuja delimitação envolve um esforço tão difícil quanto necessário, desde que se pretenda operacionalizá-lo no âmbito de uma investigação empírica (BUENO, 2014).

Weber (I9Io) define autoridade ou dominação como um poder de mando e um dever de obediência. Seria "a probabilidade de encontrar obediência de uma ordem de determinado conteúdo, entre determinadas pessoas indicáveis" (WEBER, 1990, p. 33 apud PESCAROLO e MORAES, p.I53, 2016). Para Weber não há autoridade por si, fora de uma relação e, para que haja autoridade é necessário que ao mesmo tempo haja alguém interessado em obedecer.

Richard Sennett, por exemplo, tem um livro só sobre o tema. Para Sennett (2001), autoridade está relacionada com algumas qualidades como, autocontrole, segurança (não intransigência), capacidade superior de julgamento, desenvoltura, exemplo, afeto, exigência e força. Alguém que tem autoridade é “alguém que tem força e a usa para guiar os outros, disciplinando-os e modificando seu modo de agir, através da referência a um padrão superior” (SENNETT, 20or, p.30 apud PESCAROLO e MORAES, p.155, 2016).

Para Jean Piaget (1994, apud PESCAROLO e MORAES (2016), a autoridade do adulto é o que possibilita o desenvolvimento da autonomia da criança. Autonomia seria a capacidade de coordenação de diferentes perspectivas sociais com o pressuposto do respeito recíproco. Porém, num primeiro momento, Piaget destaca a necessidade de coação e obediência no cenário das relações sociais infantis, pois o eixo central do desenvolvimento moral é a passagem da heteronomia para a autonomia. 
Em sua acepção comum, o termo autoridade nos remete, de acordo com o Dicionário Aurélio (FERREIRA, 200I, p. 84 apud BUENO, 2014, p.16), às noções de "poder legítimo, direito de mandar [...] ascendência, influência resultante de estima, de pressão moral, [...] opinião abalizada na qual uma pessoa se apoia, [ou ainda] representantes do poder público e altos funcionários”. Para Bourdieu e Passeron (1992 apud Bueno, 2014), toda ação pedagógica corresponde a uma violência simbólica, na medida em que exerce a imposição de um determinado arbitrário cultural.

É nesse sentido que se torna possível afirmar, de acordo com a perspectiva adotada por Bourdieu e Passeron (1992 apud BUENO, 2014), que o fundamento que confere legitimidade à autoridade pedagógica está necessariamente condicionado a uma violência simbólica, na medida em que tanto o poder que assimetriza as relações pedagógicas entre professores e alunos quanto a seleção dos conteúdos transmitidos nessas relações são processos arbitrários que, no entanto, aparecem dissimulados no cotidiano da vida escolar.

$\mathrm{Na}$ sociedade atual, a autoridade não estaria ancorada mais tão intensamente nos mesmos símbolos em que estava no século XIX e início do XX. Houve também nos últimos séculos, e principalmente nas últimas décadas, uma aproximação afetiva e psíquica entre as gerações (ARIÈS, 2006 apud PESCAROLO e MORAES, 2016). A centralidade da infância e a aproximação afetiva entre pais e filhos, professores e alunos, faz com que a autoridade seja colocada em outra chave. Arendt (1992, p. 243-244 apud Pescarolo e Moraes, p.158, 2016) concorda ao dizer:

\footnotetext{
A crise da autoridade na educação guarda a mais estreita conexão com a crise da tradição, ou seja, com a crise de nossa atitude perante o âmbito do passado. É sobremodo difícil para o educador arcar com esse aspecto da crise moderna, pois é de seu ofício servir como mediador entre o velho e o novo, de tal modo que sua própria profissão the exige um respeito extraordinário pelo passado.
}

Em outros tempos, a autoridade docente contava com o consentimento dos alunos, que viam a escola como uma oportunidade dourada para seu futuro. Atualmente, com a crise da função da escola, o professor parece ocupar uma posição de impostor. Por um lado, ele materializa o fracasso profissional, já que o salário que recebe, às vezes, mal possibilita uma vida digna (apud PESCAROLO e MORAES, 20r6). 
Yves de La Taille (1999, apud CARNEIRO, 2015) apresenta a relação professor/aluno como uma relação hierárquica na qual se assenta a autoridade do primeiro, que organiza o processo de ensino por meio de ordens e diretivas e que, por sua vez, para que ocorra a aprendizagem, o aluno deve segui-las, desde que sejam justas e corretas. Para Yves de La Taille (1999), o tema da autoridade é bastante complexo, já que envolve relações de poder determinadas política, econômica e culturalmente.

Para Carneiro (2015), no contexto escolar, o professor se baseia no diálogo, na confiança e na solução democrática dos conflitos, a afetividade se fortalece e a relação de autoridade pode se exercer pelo respeito e admiração dos alunos; neste caso, o que prepondera não é o medo da punição, mas o medo de perder o respeito da pessoa admirada, no caso o professor.

Para Araújo (1999 apud CARNEIRO, 2015), a construção da autoridade no contexto escolar, deve se pautar na reflexão constante no modo como a escola estrutura as relações interpessoais e como ela se organiza pedagogicamente em espaços e tempos de aprendizagem.

É no encontro diário entre os sujeitos professor e estudante e no entrecruzamento de desejos e expectativas que ambos se constituem como sujeito e objeto de ensino. É na interação que o ato comum de aprender se dá, para o estudante como espaço de construção do conhecimento e, para o professor, espaço de sua (re)construção. Este é, contudo, um "campo prenhe de pequenos enfrentamentos cotidianos" (AQUINO, I999, p. I42 apud CARNEIRO,2015, p.42).

\section{4- A CONSTRUÇÃO DE PRÁTICAS PARTICIPATIVAS}

A Pedagogia Participativa, também definida como aprendizagem em participação, permite o livre desenvolvimento da personalidade da criança. É a estruturação de um contexto educativo democrático, em parceria com uma estrutura de trabalho cooperativo, no qual a construção das aprendizagens ocorre em circuitos de diálogo, reflexão e comunicação. Na pedagogia Participativa, tanto a criança, quanto o adulto e o próprio território são sujeitos ativos da aprendizagem (Educação Não para, 2020). 
Para se garantir uma Pedagogia Participativa é preciso escutar a criança. Escutar crianças é um gesto sensível, que ultrapassa a ação, embora tenha início com ela. É um processo que demanda atenção, cuidado e, principalmente, disponibilidade - não só de tempo, mas de afeto. No lugar das atividades prontas, em que quem propõe é o professor, numa Pedagogia Participativa são as crianças as primeiras disparadoras das ações pedagógicas (Educação Não para, 2020).

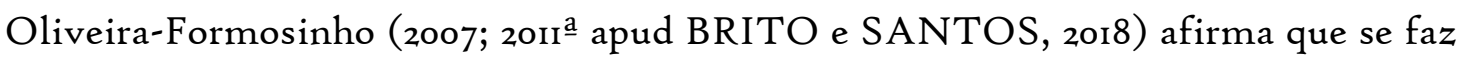
necessário o desenvolvimento das linguagens das crianças no processo de fala e escuta na coparticipação entre os sujeitos da aprendizagem envolvida. Os principais processos da Pedagogia da Participação são a observação, a escuta e a negociação (OLVEIRAFORMOSINHO, 2007; 2011 ${ }^{\mathrm{a}}$ apud BRITO e SANTOS, 2018), como especificado a seguir:

A observação se constitui no processo contínuo que busca o conhecimento de cada criança individualmente que envolve a aprendizagem e o desenvolvimento. A observação precisa compreender os diversos contextos envolvidos: família, comunidade, sociedade e escola. Nesse processo, entende-se que é necessário que o professor observe o brincar das crianças, pois, são fontes de pesquisa para a compreensão da ação e aprendizagem da criança.

A observação está presente no cotidiano da práxis pedagógica que deve ser cuidadosa e partilhada no ambiente escolar. Ainda, define-se que a observação é um processo que se constrói na participação e na reflexão, que não se faz isoladamente, mas em partilha com os envolvidos no processo de aprendizagem e desenvolvimento da criança (BRITO e SANTOS, 2018).

A escuta fundamenta-se no processo de ouvir as crianças que parte da construção da experiência vivida. Assim como a observação também é um processo contínuo que envolve a busca da experiência sobre a criança, seus interesses, interações, desejos e saberes. A escuta está relacionada ao ato de compreender uma mensagem onde o educador pode reconstruir várias atitudes (OLIVEIRA-FORMOSINHO, 2007; 201 ${ }^{\underline{a}}$ apud BRITO e SANTOS, 2018). 
A escuta parte de um processo contínuo que busca respostas aos interesses das crianças. (OLIVEIRA-FORMOSINHO, 2007b, p.28 apud BRITO e SANTOS, 2018) considera que é "um processo que procura conhecimento sobre as crianças. Seus interesses, motivações, relações, saberes, intenções, mundo de vida, realizada no contexto da comunidade educativa procurando uma ética de reciprocidade".

A negociação constitui-se em debater e definir os processos curriculares. É decidir em contexto o que se planeja para o agrupamento. (OLIVEIRA-FORMOSINHO, 2008 apud BRITO e SANTOS, 2018) afirma que se trata de uma coparticipação entre o educador(a) e as crianças no processo de construção do planejamento curricular, que ultrapassa a sala e muitas vezes envolvem a família no contexto de participação.

Oliveira-Formosinho (2007; 20Ira) afirma que a Pedagogia da Participação reside na integração das crenças e dos saberes, da teoria e da prática, da ação e dos valores. Essa integração parte do resultado do espaço de ação e reflexão, bem como do espaço da produção de narrativas sobre o fazer e para o fazer. A autora (OLIVEIRAFORMOSINHO, 2007, p. I8-I9 apud BRITO e SANTOS, 2018) define que:

A pedagogia da participação centra-se nos autores que constroem o conhecimento para que participem progressivamente, através do processo educativo, da (s) cultura(s) que os constituem como seres sócio-histórico culturais. A pedagogia da participação realiza um diálogo constante entre a intencionalidade conhecida para o ato educativo e a sua prossecução no contexto com os autores, porque esses são pensados como ativos, competentes e com direito a Co definir o itinerário do projeto de apropriação da cultura que chamamos de educação.

É imprescindível pensar, de forma integrada, as diversas dimensões pedagógicas, uma vez que se considera que a qualidade dessas dimensões tem impacto diferenciado na Co construção das aprendizagens das crianças. Considera-se também que não existem dimensões pedagógicas neutras porque a forma como se pensa e materializa as dimensões centrais da pedagogia contém uma visão do mundo, da vida, do homem, da sociedade, do conhecimento, e especificamente da relação entre a criança e o conhecimento (OLIVEIRA-FORMOSINHO, 2016). 


\section{CONSIDERAÇÕES FINAIS}

O presente estudo teve como objetivo de desenvolver uma reflexão sobre a formação do corpo estudantil ao tratar crianças da educação infantil e identificar as violências no contexto escolar. Pudemos compreender que dentro deste ambiente ocorre uma variedade de ações pautadas em agressividade. No entanto, alguns autores citados acima afirmam que a violência escolar não se resume apenas as agressões físicas.

A escolha desse tema para trabalho de conclusão de curso teve como intuito buscar entender como a violência e a violência simbólica é presente nas escolas. Com isso, podemos concluir que a escola necessita de uma mudança no sistema educacional, principalmente com a inclusão da Pedagogia Participativa, pois tanto a criança, quanto o educador e o próprio território são sujeitos ativos da aprendizagem.

Esta questão precisa ser debatida para que possa ser combatida pela comunidade escolar, através da conversa, atividades, a escuta, o diálogo e não apenas fazer da escola um lugar que aprenda só conteúdo. Por isso é de extrema importância estar por dentro do que acontece no cotidiano da escola e o trabalho a ser realizado através de diagnósticos para a construção de projetos de intervenção e convivência escolar, para melhorar o ambiente convivido.

É importante saber que os programas de prevenção e intervenção da violência escolar ampliem a definição sobre as variáveis que podem constituir a violência, englobando reflexões sobre a realidade concreta da vida do estudante, das famílias e dos professores. Tendo ciência de que essa prevenção precisa estar contextualizada com a realidade local escolar, na medida em que a violência deve ser compreendida a partir do contexto social e cultural que está inserida.

\section{REFERÊNCIA}

ABRAMOVAY, Miriam. Programa de prevenção à violência nas escolas: Violências nas Escolas. FLACSO BRASIL, 2015.

ASSIS, Simone Gonçalves de. Impactos da violência na escola: um diálogo com professores. Rio de Janeiro: Ministério da Educação / Editora FIOCRUZ, 2010. 
BUENO, Fabricio Aparecido. A autoridade docente no cotidiano da sala de aula: um enfoque na perspectiva de alunos de uma turma de ensino fundamental. São João del-Rei, 2014.

BRITO, Ângela do Céu Ubaiara; SANTOS, Maria Letícia Ribeiro dos. O brincar na Pedagogia- em -participação. Universidade de São Paulo - USP, 2018.

CANDIDO, Everson Adilio. Violência escolar: um olhar sobre as condições de violência vivenciadas por professores no ambiente escolar. Repositório Institucional da UFSCar Florianópolis, 2019.

CARNEIRO, Flavia Helena Pontes. Autoridade e disciplina na escola: reflexões sobre de construção da autoridade no contexto de formação de monitores. Revista Recife, v.I.n.I.p.33-45, 2015. CapUFPE.

Educação Não Para. Entendendo a educação infantil: PEDAGOGIA PARTICIPATIVA E PEDAGOGIA DA ESCUTA. Disponível em: <https://educacaonaopara.com/wpcontent/uploads/2020/o4/Pedagogia-paticipativa-e-escuta.pdf $>$ Acesso em: 09/o9/2021

FAZZI, R. de C. O Drama Racial das Crianças Brasileiras: socialização entre pares e preconceito. Belo Horizonte: Editora Autêntica, 2006.

JUBÉ, Milene de Oliveira Machado Ramos et al; Violência simbólica e cultura da paz: uma leitura Bourdiesiana. Brazilian Journal of Development, Curitiba, v.7, n.3, p. 24873$24889 \mathrm{feb} / \mathrm{mar} 202 \mathrm{I}$.

MONTEIRO, Solange Aparecida de Souza; RIBEIRO, Paulo Rennes Marçal. Sexualidade e Gênero na atual BNCC: possibilidades e limites. Barreiras (BA), v. I, ezozoII, p. I-24, 2020 .

OLIVEIRA-FORMOSINHO, Júlia. As gramáticas pedagógicas participativas e a construção da identidade da criança. Associação Criança e Universidade Católica Portuguesa, v.18, n.36, 2016.

PEREIRA, Antonio Igo Barreto. Autoridade enfraquecida, violência escolar e trabalho pedagógico: a percepção de professores sobre a ruptura dos vínculos de afeto e os malestares no magistério. Repositório Institucional UFSCar: UFSCar, 2016.

PESCAROLO, Joyce Kelly; MORAES, Pedro Rodolfo Bodê de. O declínio da autoridade docente na escola contemporânea. Rev. Diálogo Educ., Curitiba, v. 16, n. 47, p. 147-168, jan./abr. 2016.

Disponpível em 
https://periodicos.pucpr.br/index.php/dialogoeducacional/article/view/rg99>. Acesso em 13/05/2021

SOUZA, Samara Barroso Batista. A influência da violência na interação professor-aluno. Campos dos Goytacazes; Universidade federal fluminense, 2017.

TUONO, Nadiele Elias Faria; VAZ, Marta Rosani Taras. O racismo no contexto escolar e a prática docente. Vol. 9 | №. I8 | Mai./Ago, 2017 